\title{
Article \\ Confirmation of aflatoxin in fish and shrimp by LC/MS-MS (ZEVO TQD)
}

\author{
Mohammed Anwar Parvez", Md. Barkatul Alam and Md Manik Mia \\ Technologist, Technical Manager and Quality Assurance Manager, Quality Control Laboratory, Dhaka, \\ Department of Fisheries, Bangladesh \\ *Corresponding author: Mohammed Anwar Parvez, Technologist, Quality Control Laboratory, Dhaka, \\ Department of Fisheries, Bangladesh. E-mail: parvez_pappa@yahoo.co.in
}

Received: 14 April 2020/Accepted: 25 May 2020/ Published: 30 May 2020

\begin{abstract}
Mycotoxins are agricultural contaminants of fungal origin occurring at all latitudes worldwide and being characterized by acute and chronic effects on human health and animal wellness, depending on the species sensitivity. Various types of crops like maize, wheat, soybeans etc are used as raw materials for preparing feed of fish and shrimp. They are particularly susceptible to infection by Aspergillus following prolonged exposure to a high humidity environment. For this reason, the fish and shrimp samples should be tested for identifying and quantifying mycotoxin. The major mycotoxins of food concern are aflatoxin $\left(B_{1}, B_{2}, G_{1}, G_{2}\right)$ for its toxicity. This paper focus on the confirmation of aflatoxin in fish and shrimp by developing method and validated it by LC/MS-MS (ZEVO TQD) which is important for ensuring the safety of fishery product for human consumption. The monitored MRM transitions for $\mathbf{B}_{1}, \mathbf{B}_{2}, \mathbf{G}_{1}, \mathbf{G}_{2}$ were $\mathrm{m} / \mathrm{z}, 313 \rightarrow 57$ and $\mathrm{m} / \mathrm{z} 313 \rightarrow 71, \mathrm{~m} / \mathrm{z} 318 \rightarrow 88$ and $\mathrm{m} / \mathrm{z}$ $318 \rightarrow 256, \mathrm{~m} / \mathrm{z}, 328.75 \rightarrow 242.99$ and $\mathrm{m} / \mathrm{z} 328.75 \rightarrow 199.9, \mathrm{~m} / \mathrm{z} \quad 330.34 \rightarrow 88$ and $\mathrm{m} / \mathrm{z} 330.34 \rightarrow 106$ respectively. Limit of decision (CC $\alpha$ ) for $B_{1}, B_{2}, G_{1}, G_{2}$ were $0.59 \mu \mathrm{g} / \mathrm{kg}, 0.70 \mu \mathrm{g} / \mathrm{kg}, 0.68 \mu \mathrm{g} / \mathrm{kg}, 0.83 \mu \mathrm{g} / \mathrm{kg}$ respectively and detection capability $(C C \beta)$ for $B_{1}, B_{2}, G_{1}, G_{2}$ were $1.01 \mu \mathrm{g} / \mathrm{kg}, 1.19 \mu \mathrm{g} / \mathrm{kg}, 1.15 \mu \mathrm{g} / \mathrm{kg}, 1.40 \mu \mathrm{g} / \mathrm{kg}$ respectively.
\end{abstract}

Keywords: aflatoxin; CC $\alpha$ and CC $\beta$; LC-MS/MS; shrimp; fish

\section{Introduction}

Mycotoxins are toxic secondary metabolites produced by microorganisms of the fungus kingdom, commonly known as molds. The word 'mycotoxin' is commonly set aside for the toxic products produced by some fungi that readily inhabit crops (Turner et al., 2009). A mold species can yield many different mycotoxins, and numerous species could produce similar mycotoxin (Robbins et al., 2000). There are now over 400 recognized mycotoxins that may be found in animal feedings materials and it has been reported that as much as $25 \%$ of the worlds cereal grains may be contaminated with mycotoxins (Stead et al., 2014). Aflatoxins are type of mycotoxin produced by Aspergillus species of fungi, such as Aspergillus flavus and Aspergillus parasiticus (Martins et al., 2001). The word aflatoxin denotes to four different types of mycotoxins produced, which are B1, $\mathrm{B} 2, \mathrm{G} 1$, and G2. Aflatoxin B1, the utmost toxic, is a strong cancer-causing agent and has been directly linked to liver cancer in numerous animal species (Martins et al., 2001). The Aflatoxins were first rose to notoriety in 1960 when they caused the deaths of thousands of turkeys on farms in the UK. The bird feed had been made with peanut meal, imported from Brazil, which had been contaminated with the mold Aspergillus flavus. The incident highlighted the dangers posed by these compounds, dangers exacerbated by the global nature of modern agricultural trade (de Kok et al., 2007). The appearance of toxigenic fungi and the subsequent production of mycotoxins are more frequently observed in food and feed produced in developing countries. Environmental factors such as high temperature, high humidity and moisture, frequent rainfalls, and poor soil conditions play important roles in growth of fungi and thereby aflatoxin contamination of feed (Cotty and Jaime-Garcia, 2007; Iqbal et al., 2015; Shad et al., 2019). In addition, improper farm management, which includes poor harvesting techniques and unsuitable storage conditions, can contribute to high occurrence of aflatoxin contamination 
(Atungulu et al., 2019; Shad and Atungulu, 2019). Many agricultural products such as nuts ,fresh and dried fruits and vegetables, cereals such as like maize, rice, wheat and soybeans, liquids such as wine, grape juice, beer, milk and dairy products, spices and herbs, coffee, cocoa and feed can be contaminated with mycotoxins at all stages of the food and feed chain. Some of these crops like maize, wheat, rice, soybeans, nuts etc are used as raw materials for preparing feed of fish and shrimp. These fish feed are used in fresh water culture. So fish and shrimps are obviously affected with aflatoxin. It is crying need to quantify the amount of aflatoxin in order to consume safe fishery product. According to European Commission (Regulation 1881/2006), the European legislation sets maximum limits for aflatoxin $B_{1}$ is $2 \mathrm{ppb}$ and maximum limits for total aflatoxin $\left(B_{1}, B_{2}, G_{1}, G_{2}\right)$ is $4 \mathrm{ppb}$. Till to date several analytical method has been developed for quantifying Mycotoxin in different cereal based food and animal feedstuffs by using HPLC or LC/MS-MS techniques. But no method developed yet for analysing aflatoxin/Mycotoxin in shrimp and fish sample. This paper reports the development of a quantitative method for determining aflatoxin (B1, B2, G1, G2) of shrimp and fish. This method uses UPLC and ZEVO TQD (LC/MS-MS). Method was validated as per Commission Decision 2002/657/EC of 12 August 2002 implementing Council Directive (96/23/EC) establishes criteria and procedures for the validation of analytical methods to ensure the quality and comparability of analytical results generated by official laboratories.

\section{Materials and Methods}

\subsection{Standards and reagents}

Aflatoxin $B_{1}$, Aflatoxin $B_{2}$, Aflatoxin $G_{1}$, Aflatoxin $G_{2}, M_{1}$ standard ware purchased from Sigma-Aldrich (st. Louis, MO). MS grade formic acid, methanol and acetonitrile were also from Sigma-Aldrich (st. Louis, MO). Beside these HPLC grade chemicals (Ethyl acetate, Acetonitrile, Methanol), Appropriate dispersive sorbent (ZSep+) and Deionized water were used.

\subsection{Sample preparation procedure}

i. $\quad$ Take $(1 \pm 0.05) \mathrm{g}$ of blend sample in to $50 \mathrm{ml}$ centrifuge tube.

ii. $\quad$ Add $100 \mu \mathrm{l}$ from $50 \mathrm{ppb} \mathrm{M}_{1}$

iii. Add $9 \mathrm{ml}$ of $\mathrm{ACN}$

iv. Shake 10 minutes and centrifuge at $8000 \mathrm{rpm}$ for 15 minutes

v. Take $8 \mathrm{ml}$ of supernatant

vi. $\quad$ Add $90 \mu \mathrm{l}$ formic acid (MS Grade)

vii. $\quad$ Add $500 \mathrm{mg}$ Appropriate dispersive sorbent (Z-Sep+)

viii. Vortex for 5 minutes and centrifuge at 8000 rpm for 15 minutes

ix. Take $7 \mathrm{ml}$ of supernatant in a glass tube

x. Evaporate to Dryness under nitrogen gas Pressure

xi. Reconstitute by $1 \mathrm{ml}$ of $0.1 \%$ Formic acid With $10 \%$ Acetonitrile

xii. Pass the sample through a $0.45 \mu \mathrm{m}$ syringe filter and collect in a vial for subsequent LC-MS/MS analysis.

Calibration curve: For calibration curve standards preparation is described in Table 1.

Table 1. Standard preparation for calibration curve.

\begin{tabular}{|l|l|l|l|}
\hline Sl No. & Volume Mixed Std 10 ng/ml $(\boldsymbol{\mu l})$ & Volume $\mathbf{M}_{\mathbf{1}}$ ISTD 50 ng/ml $(\boldsymbol{\mu l})$ & Std Equivalent Concentration $(\mathbf{p p b})$ \\
\hline 1 & 0 & 100 & 0.00 \\
\hline 2 & 50 & 100 & 0.5 \\
\hline 3 & 100 & 100 & 1 \\
\hline 4 & 150 & 100 & 1.5 \\
\hline 5 & 200 & 100 & 2 \\
\hline 6 & 300 & 100 & 3 \\
\hline 7 & 400 & 100 & 4 \\
\hline 8 & 500 & 100 & 5 \\
\hline
\end{tabular}

\subsection{Chromatography conditions}

LC/MS-MS Module: Acquity UPLC ZEVO TQD (Waters, USA)

Column: Acquity UPLC BEH C18 $1.7 \mu \mathrm{m}, 2.1 \times 100 \mathrm{~mm}$ column, Waters, made in Ireland.

Column Temperature: Ambient. 
Mobile phase: Pump A: 0.1\% FA in water, Pump B: 0.1\% FA in Acetonitrile.

Inlet method: Inlet method is created according to Gradient system as described in Table 2.

Table 2. Gradient table.

\begin{tabular}{|l|l|l|l|l|l|}
\hline $\begin{array}{l}\text { SL } \\
\text { No. }\end{array}$ & Time & $\begin{array}{l}\text { Pump A/0.1\% Formic Acid in } \\
\text { Water }\end{array}$ & $\begin{array}{l}\text { Pump B/0.1\% Formic Acid in } \\
\text { Acetonitrile }\end{array}$ & Flow (ml/min) \\
\hline 1 & 0.00 & 90 & 90 & 10 & 0.4 \\
\hline 2 & 3.0 & 10 & 90 & 0.4 \\
\hline 3 & 10 & 10 & 90 & 0.4 \\
\hline 4 & 10.10 & 10 & 90 & 50 & 0.4 \\
\hline 5 & 12 & 80 & 20 & 0.4 \\
\hline 6 & 12.10 & 90 & 10 & 0.4 \\
\hline 7 & 13.10 & 90 & 10 & 0.4 \\
\hline 8 & 14 & 15 & & 90 & 0.4 \\
\hline 9
\end{tabular}

Flow $(\mathrm{ml} / \mathrm{min}) \quad: 0.4$

Injection Volume $(\mu \mathrm{l}) \quad: 15$ (Full loop)

\subsection{MS condition}

Mass Spectrometer: ZEVO TQD (Waters, USA)

$\begin{array}{ll}\text { Source (ESP+) } & : 4 \\ \text { Capillary (kv) } & : 42 \\ \text { Cone (v) } & : 3 \\ \text { Extractor (v) } & : 0.2 \\ \text { RF Lens } & : 135 \\ \text { Source Temp }\left({ }^{\circ} \mathrm{c}\right) & : 400 \\ \text { Dessolvation Temp }\left({ }^{\circ} \mathrm{c}\right) & : 900 \\ \text { Desolvation gas flow (L/h) } & : 50 \\ \text { Cone gas flow (L/h) } & \\ & \\ \text { Analyser } & : 9.7 \\ \text { LM Resolution 1 } & : 15 \\ \text { HM Resolution 1 } & : 0.2 \\ \text { Ion Energy 1 } & : 50 \\ \text { Entrance voltage } & : 50 \\ \text { Exit voltage } & : 10.8 \\ \text { LM Resolution 2 } & : 14.9 \\ \text { HM Resolution 2 } & : 0.7 \\ \text { Ion Energy 2 } & : 650 \\ \text { Multiplier voltage } & : \text { Argon @ } 3.5 \times 10^{-3} \text { mbar } \\ \text { Collision gas } & : 0.00 \\ \text { Span (Daltons) } & : 0.030 \\ \text { Dwell time (Sec) } & : 0.02 \\ \text { Inter Channel Delay (Sec) } & : 0.02 \\ \text { Inter-Scan Delay (Sec) } & \end{array}$




\section{Results and Discussion}

Nowadays, MS/MS is used for accurate mass information (Pascale et al., 2019) and the LC-tandem MS (MS/MS) technique is considered to be the most modern and widely used for mycotoxins analysis at trace levels, as it is more sensitive, specific and reliable compared to HPLC (Woo et al., 2019; Bessaire et al., 2019; Al-Taher et al., 2017). This technique has been successfully used for the simultaneous quantification of mycotoxins with different chemical structures (Zhang et al., 2018) in one single run (Spanjer et al., 2008; Delmulle et al., 2006). The developed MS method (Table 3) for Aflatoxin $\left(\mathrm{B}_{1}, \mathrm{~B}_{2}, \mathrm{G}_{1}, \mathrm{G}_{2}\right)$ has a good agreement with these previous findings as mentioned above. The separation of each individual aflatoxin from its mixture is very clear as shown in chromatogram (Figure 1 and Figure 2). Aflatoxin $\left(B_{1}, B_{2}, G_{1}, G_{2}\right)$ in Shrimp and Fish matrix was quantified by means of a calibration curve (Figure 3 ) at seven calibration levels ranging $0.5 \mathrm{ppb}$ to $5.0 \mathrm{ppb} . \mathrm{M}_{1}$ is used as internal standard. Solvent blank, matrix blank, negative and positive control samples are used each analytical batch as an internal quality control measures.

Table 3. MRM transitions and MS condition.

\begin{tabular}{|l|l|l|l|l|l|l|l|}
\hline SL. No. & Prnt(Da) & Dau(Da) & Dwell(s) & Cone(v) & Coll(eV) & Delay(s) & Compound \\
\hline 1 & 313 & 57 & 0.030 & 40 & 34 & 0.02 & $\mathrm{~B}_{1}$ \\
\hline 2 & 313 & 71 & 0.030 & 40 & 34 & 0.02 & $\mathrm{~B}_{1}$ \\
\hline 3 & 318 & 88 & 0.030 & 46 & 30 & 0.02 & $\mathrm{~B}_{2}$ \\
\hline 4 & 318 & 256 & 0.030 & 46 & 30 & 0.02 & $\mathrm{~B}_{2}$ \\
\hline 5 & 328.75 & 242.99 & 0.030 & 40 & 30 & 0.02 & $\mathrm{G}_{1}$ \\
\hline 6 & 328.75 & 199.9 & 0.030 & 40 & 30 & 0.02 & $\mathrm{G}_{1}$ \\
\hline 7 & 330.34 & 88 & 0.030 & 56 & 28 & 0.02 & $\mathrm{G}_{2}$ \\
\hline 8 & 330.34 & 106 & 0.030 & 56 & 28 & 0.02 & $\mathrm{G}_{2}$ \\
\hline 9 & 328.76 & 273.03 & 0.030 & 32 & 20 & 0.02 & $\mathrm{M}_{1}$ (ISTD) \\
\hline
\end{tabular}

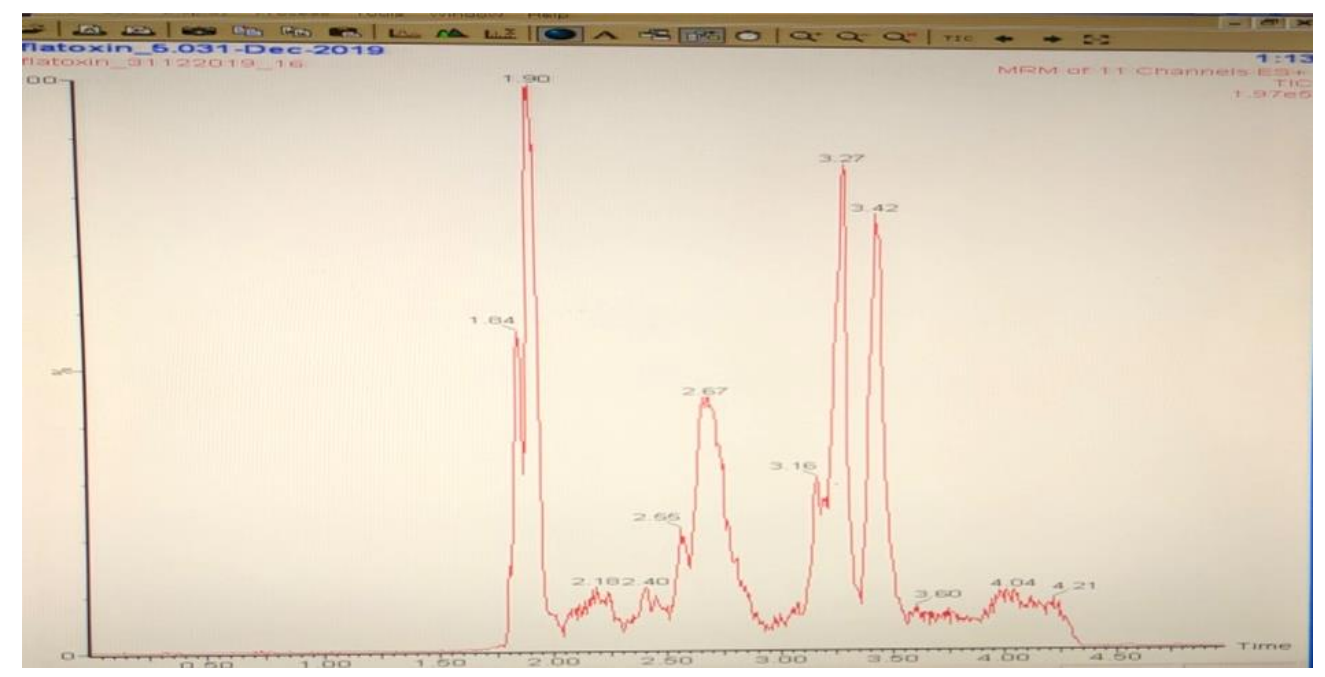

Figure 1. UPLC/MS-MS chromatogram of mixed aflatoxin. 


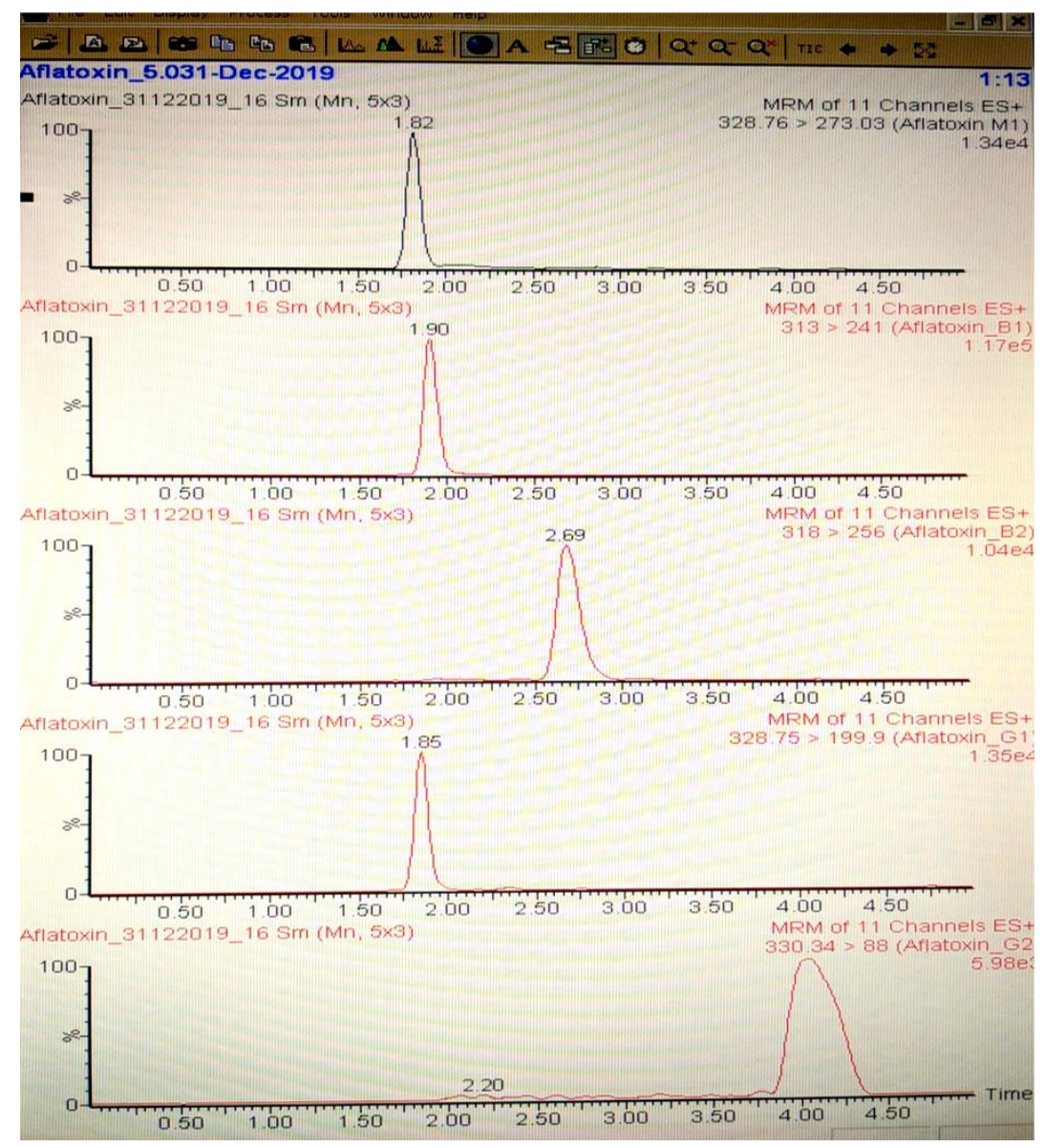

Figure 2. UPLC/MS-MS chromatograms of individual aflatoxin.

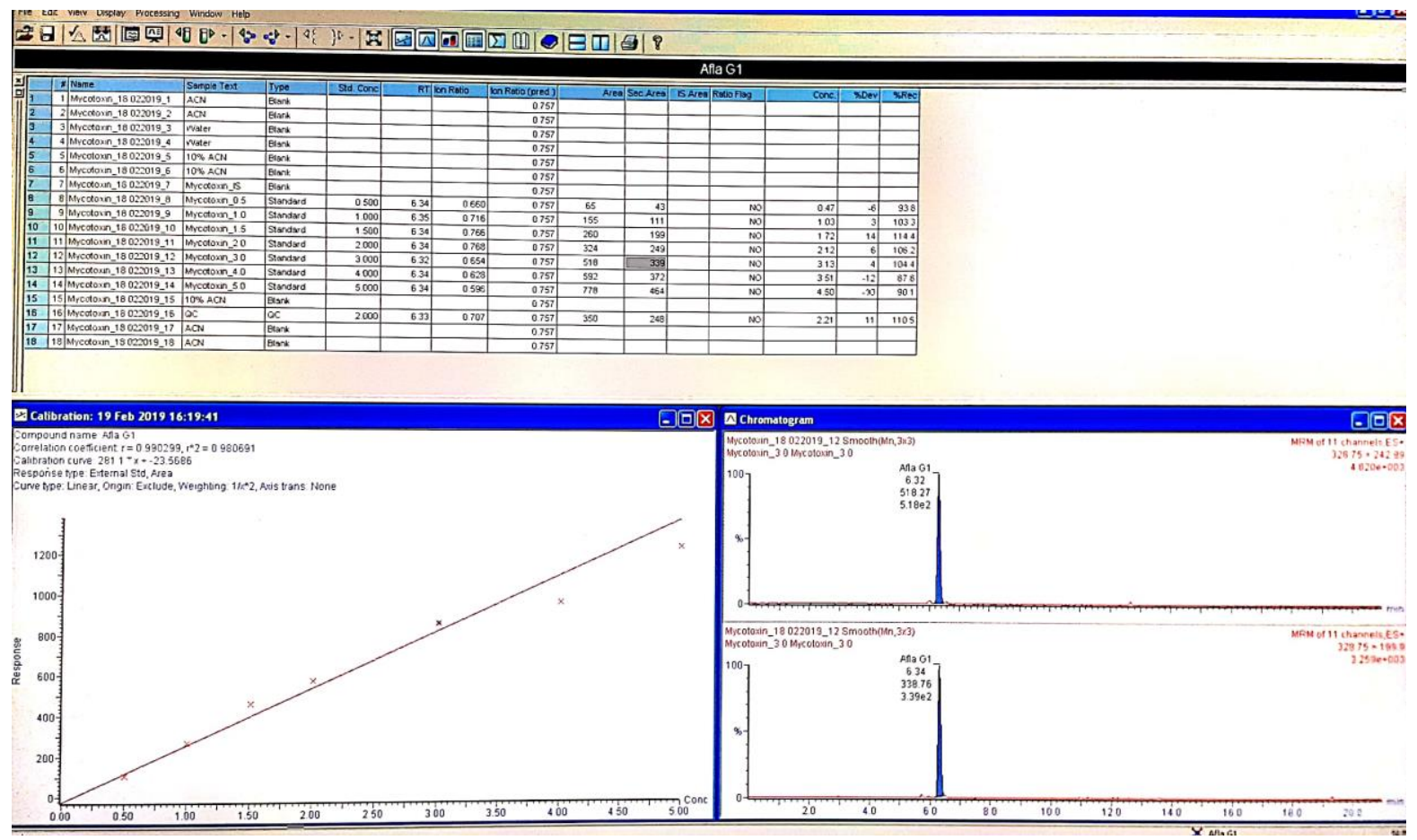

Figure 3. TargetLynx report of calibration curve of aflatoxin $\left(B_{1}, B_{2}, G_{1}, G_{2}\right)$ in shrimp and fish. 


\subsection{Confirmation criteria}

The selectivity of this method is judged by the use of two transitions for each analyte which count for 4 identification points (IPs), as defined by the EU criteria set out in Commission Decision 2002/657/EC. This method fulfills this requirement. The Aflatoxin $\left(B_{1}, B_{2}, G_{1}, G_{2}\right)$ was considered as positively identified in the samples when the peak area ratio of the various transitions was within the tolerance set by Commission Decision 2002/657/EC. In addition, the relative retention time of the analyte must be equal to that of the calibration standard to within $\pm 2.5 \%$.

\subsection{Validation}

CC $\alpha$ \& CC $\beta$ were calculated using the procedure set out in ISO Guide 11843, as described in Commission Decision 2002/657/EC. The validation data were generated in 4 levels of concentrations i.e. $1.0 \mathrm{ppb}, 2.0 \mathrm{ppb}$, $3.0 \mathrm{ppb}, 4.0 \mathrm{ppb}$ with seven replicates per level for 3 different days using fish \& shrimp as matrix. The values are shown in the table.

\begin{tabular}{|l|l|l|}
\hline Analyte & $\mathbf{C C} \boldsymbol{\alpha}(\boldsymbol{\mu g} / \mathbf{k g})$ & $\mathbf{C C} \boldsymbol{\beta}(\boldsymbol{\mu g} / \mathbf{k g})$ \\
\hline Aflatoxin $\mathrm{B}_{1}$ & 0.59 & 1.01 \\
\hline Aflatoxin $\mathrm{B}_{2}$ & 0.70 & 1.19 \\
\hline Aflatoxin $\mathrm{G}_{1}$ & 0.68 & 1.15 \\
\hline Aflatoxin $\mathrm{G}_{2}$ & 0.83 & 1.40 \\
\hline
\end{tabular}

Overall summary of the validation data calculation:

\begin{tabular}{|c|c|c|c|c|c|c|}
\hline \multicolumn{7}{|c|}{ B1 in Shrimp and Fish } \\
\hline Fortification Level & $\begin{array}{l}\text { Overall } \\
(\mu \mathrm{g} / \mathrm{kg})\end{array}$ & Mean & $\begin{array}{l}\text { Overall } \\
\text { Recovery (\%) }\end{array}$ & $\begin{array}{l}\text { Within Day } \\
\text { CV }\end{array}$ & $\begin{array}{l}\text { Between } \\
\text { Day CV }\end{array}$ & Intermediate Precision CV \\
\hline 1.00 & 0.83 & & 83 & 7.3 & 3.0 & 7.9 \\
\hline 2.00 & 1.67 & & 84 & 5.7 & 4.0 & 7.0 \\
\hline 3.00 & 3.01 & & 100 & 4.4 & 1.9 & 4.8 \\
\hline 4.00 & 4.48 & & 112 & 2.8 & 3.6 & 4.6 \\
\hline
\end{tabular}

$\begin{array}{lllllll}\text { B2 in Shrimp and Fish } & & & & \\ \text { Fortification Level } & \begin{array}{l}\text { Overall } \\ (\mu \mathrm{g} / \mathrm{kg})\end{array} & \text { Mean } & \begin{array}{l}\text { Overall } \\ \text { Recovery }(\%)\end{array} & \begin{array}{l}\text { Within } \\ \text { CV }\end{array} & \begin{array}{l}\text { Between } \\ \text { Day CV }\end{array} & \begin{array}{l}\text { Intermediate Precision CV } \\ 1.00\end{array} \\ 1.12 & 112 & 5.4 & 2.2 & 5.9 & \\ 2.00 & 2.07 & 104 & 4.6 & 3.2 & 5.7 & \\ 3.00 & 2.70 & 90 & 4.9 & 2.1 & 5.4 \\ 4.00 & 3.26 & 81 & 3.8 & 4.9 & 6.3\end{array}$

\begin{tabular}{|c|c|c|c|c|c|c|}
\hline \multicolumn{7}{|c|}{ G1 in Shrimp and Fish } \\
\hline Fortification Level & $\begin{array}{l}\text { Overall } \\
(\mu g / k g)\end{array}$ & Mean & $\begin{array}{l}\text { Overall } \\
\text { Recovery (\%) }\end{array}$ & $\begin{array}{l}\text { Within Day } \\
\text { CV }\end{array}$ & $\begin{array}{l}\text { Between } \\
\text { Day CV }\end{array}$ & Intermediate Precision CV \\
\hline 1.00 & 1.09 & & 109 & 5.6 & 2.3 & 6.0 \\
\hline 2.00 & 2.17 & & 109 & 4.4 & 3.1 & 5.4 \\
\hline 3.00 & 2.86 & & 95 & 4.6 & 2.0 & 5.1 \\
\hline 4.00 & 3.58 & & 89 & 3.5 & 4.5 & 5.7 \\
\hline
\end{tabular}

\begin{tabular}{|c|c|c|c|c|c|c|}
\hline \multicolumn{7}{|c|}{ G2 in Shrimp and Fish } \\
\hline Fortification Level & $\begin{array}{l}\text { Overall } \\
(\mu \mathrm{g} / \mathrm{kg})\end{array}$ & Mean & $\begin{array}{l}\text { Overall } \\
\text { Recovery (\%) }\end{array}$ & $\begin{array}{l}\text { Within Day } \\
\text { CV }\end{array}$ & $\begin{array}{l}\text { Between } \\
\text { Day CV }\end{array}$ & Intermediate Precision CV \\
\hline 1.00 & 1.05 & & 105 & 5.8 & 2.3 & 6.2 \\
\hline 2.00 & 1.82 & & 91 & 5.3 & 3.7 & 6.4 \\
\hline 3.00 & 2.59 & & 86 & 5.1 & 2.2 & 5.6 \\
\hline 4.00 & 3.54 & & 88 & 3.5 & 4.6 & 5.8 \\
\hline
\end{tabular}




\section{Conclusions}

The method was developed and validated as per guideline and commission decision 2002/657/EC. The recovery, linearity and other parameters explains that the developed method is good enough for the confirmatory analysis of Aflatoxin $\left(B_{1}, B_{2}, G_{1}, G_{2}\right)$ by LC/MS-MS in fish \& shrimp matrix.

\section{Acknowledgements}

I would like express my gratitude and great pleasure to Quality Control Lab, Dhaka, Department of Fisheries, Bangladesh to execute this research work.

\section{Conflict of interest}

None to declare

\section{References}

Al-Taher F, J Cappozzo, J Zweigenbaum, H Lee, LS Jackson and D Ryu, 2017. Detection and quantitation of mycotoxins in infant cereals in the U.S. market by LC-MS/MS using a stable isotope dilution assay. Food Control, 72: 27-35.

de Kok A, M Spanjer, J Scholten, P Rensen and G Kearney, 2007. Rapid multi mycotoxin analysis using Acquity UPLC and Quatro Premier XE. Waters application note, Waters Corporation. Produced in the U.S.A. August 2007, 7200001996EN LB-PDF

Atungulu GG, RE Kolb, J Karcher and ZM Shad, 2019. Postharvest technology: Rice storage and cooling conservation. In J. Bao (Ed.), Rice (4th ed., pp. 517-555). AACC Int. Press.

Bessaire T, C Mujahid, P Mottier and A Desmarchelier, 2019. Multiple Mycotoxins Determination in Food by LC-MS/MS: An International Collaborative Study. Toxins, 11: 658.

Commission Regulation (EC) No 1881/2006 of 19 December 2006. Setting maximum levels for certain contaminants in foodstuffs (Text with EEA relevance), Off. J. Eur. Commun., L 364, 20.12.2006, pp. 5-24.

Cotty PJ and R Jaime-Garcia, 2007. Influences of climate on aflatoxin producing fungi and aflatoxin contamination. Int. J. Food Microbiol., 119: 109-115.

Commission Decision No 96/23/EC of 12 August 2002. Implementing Council Directive 96/23/EC Concerning the performance of analytical methods and the interpretation of results, notified under document number C(2002)3044, Text with EEA relevance,2002/657/EC, Official J., L221, 17.08.2002,p.8.

Delmulle BS, S De Saeger, A Adams, N De Kimpe and C Van Peteghem, 2006. Development of a liquid chromatography/tandem mass spectrometry method for the simultaneous determination of 16 mycotoxins on cellulose filters and in fungal cultures. Rapid Commun. Mass Spectrom. 20: 771-776.

Iqbal SZ, S Jinap, AA Pirouz and ARA Faizal, 2015. Aflatoxin M1 in milk and dairy products, occurrence and recent challenges: A review. Trends Food Sci. Technol., 46: 110-119.

Madigan M and J Martinko, 2005. Brock Biology of Microorganisms (11th ed.). Prentice Hall. ISBN 0-13144329-1.

ZM Shad, E Steen, F Devlieghere, A Mauromoustakos and GG Atungulu, 2019. Biochemical changes associated with electron beam irradiation of rice and links to kernel discoloration during storage. Cereal Chem., 1-12.

ZM Shad and GG Atungulu, 2019. Post-harvest kernel discoloration and fungi activity in long-grain hybrid, pureline and medium-grain rice cultivars as influenced by storage environment and antifungal treatment. J. Stored Prod. Res., 81: 91-99.

Pascale M, A De Girolamo, V Lippolis, J Stroka, HGJ Mol and VMT Lattanzio, 2019. Performance evaluation of LC-MS methods for multimycotoxin determination. J. AOAC Int., 102: 1708-1720.

Robbins C, LJ Swenson, L Nealley, R Gots and B Kelman, 2000. Health effect of mycotoxins in indoor air: a critical review. Appl. Occup. Environ. Hyg., 15: 77384.

Stead S, D Roberts, A Gledhill, T de Rijk, CV Poucke and S De Saeger, 2014. The development of a sensitive Multi-Residue LC/MS-MS Method for quantitive determination of mycotoxins in animal feedstuffs and silage using Xevo TQ-S.Waters application note, Waters Corporation. produced in the U.S.A. 2014,720004961EN AG-PDF.

Spanjer MC, PM Rensen, JM Scholten, 2008. LC-MS/MS multi-method for mycotoxins after single extraction,with validation data for peanut, pistachio, wheat, maize, cornflakes, raisins and figs. Food Addit. Contam. Part A 25: 472-489.

Turner N, S Subrahma and S Piletsky, 2009. Analytical methods for determination of mycotoxins: a review. Anal. Chim. Acta., 632: 168-180. 
Woo SY, S Ryu, F Tian, SY Lee, S Park and HS Chun, 2019. Simultaneous Determination of Twenty Mycotoxins in the Korean Soybean Paste Doenjang by LC-MS/MS with Immunoa_nity Cleanup. Toxins, 11: 594.

Zhang L, XW Dou, C Zhang, A Logrieco and M Yang, 2018. A review of current methods for analysis of mycotoxins in herbal medicines. Toxins, 10: 65 . 